\title{
Sanger Brown and Edward Schäfer before Heinrich Kliuver and Paul Bucy: their observations on bilateral temporal lobe ablations
}

\author{
Prasad S. S. V. Vannemreddy, MD, ${ }^{1}$ and James L. Stone, MD² \\ 1'Department of Neurosurgery, University of Illinois at Chicago, Illinois; and 2Department of Neurosurgery, NYU Langone Medical \\ Center, New York, New York
}

Fifty years before a report on the complete bitemporal lobectomy syndrome in primates, known as the Klüver-Bucy syndrome, was published, 2 talented investigators working at the University College in London, England-neurologist Sanger Brown and physiologist Edward Schäfer-also made this discovery. The title of their work was "An investigation into the functions of the occipital and temporal lobes of the monkey's brain," and it involved excisional brain surgery in 12 monkeys. They were particularly interested in the then-disputed primary cortical locations relating to vision and hearing. However, following extensive bilateral temporal lobe excisions in 2 monkeys, they noted peculiar behavior including apparent loss of memory and intelligence resembling "idiocy." These investigators recognized most of the behavioral findings that later came to be known as the Klüver-Bucy syndrome. However, they were working within the late-19th-century framework of cerebral cortical localizations of basic motor and sensory functions.

Details of the Brown and Schäfer study and a glimpse of the neurological thinking of that period is presented. In the decades following the pivotal work of Klüver and Bucy in the late 1930s, in which they used a more advanced neurosurgical technique, tools of behavioral observations, and analysis of brain sections after euthanasia, investigators have elaborated the full components of the clinical syndrome and the extent of their resections.

Other neuroscientists sought to isolate and determine the specific temporal neocortical, medial temporal, and deep limbic structures responsible for various visual and complex behavioral deficits. No doubt, Klüver and Bucy's contribution led to a great expansion in attention given to the limbic system's role in action, perception, emotion, and affect-a tide that continues to the present time.

https://thejns.org/doi/abs/10.3171/2017.6.FOCUS17265

KEY WORDS temporal lobectomy; neuropsychology; Klüver-Bucy syndrome; visual agnosia; limbic system

Those who do not remember the past are condemned to repeat it.

$$
\text { - George Santayana (1863-1952) }
$$

Sanger Brown (1852-1928) (Fig. 1) was born in Ontario, Canada. After his graduation from Bellevue Hospital Medical College in New York City, he joined Bloomingdale Asylum for the Insane in White Plains, New York, in 1882. Before going to Chicago, Brown studied with E. A. Schäfer, a noted professor of physiology at London's University College. Their experiments on monkeys demonstrated the visual center in the occipital lobe and, most importantly, established a number of temporal lobe functions. By 1890 he had settled in Chicago as a professor of neurology at the Postgraduate Medical School and as attending neurologist at a number of local hospitals, and he had also described a form of cerebellar ataxia. Brown was an organizer and the first president of the Chicago Neurological Society; he was a highly active and respected neuropsychiatrist for many years. ${ }^{10}$

Sir Edward A. E. Schäfer (1850-1935) (Fig. 2) was a noted English physiologist and is regarded as the founder of endocrinology, when he first discovered and demonstrated the existence of adrenaline along with George Oliver. Schäfer also coined the words "endocrine" and "insulin." He was a student of William Sharpey, also a physiologist at the University College of London, who was inducted into 


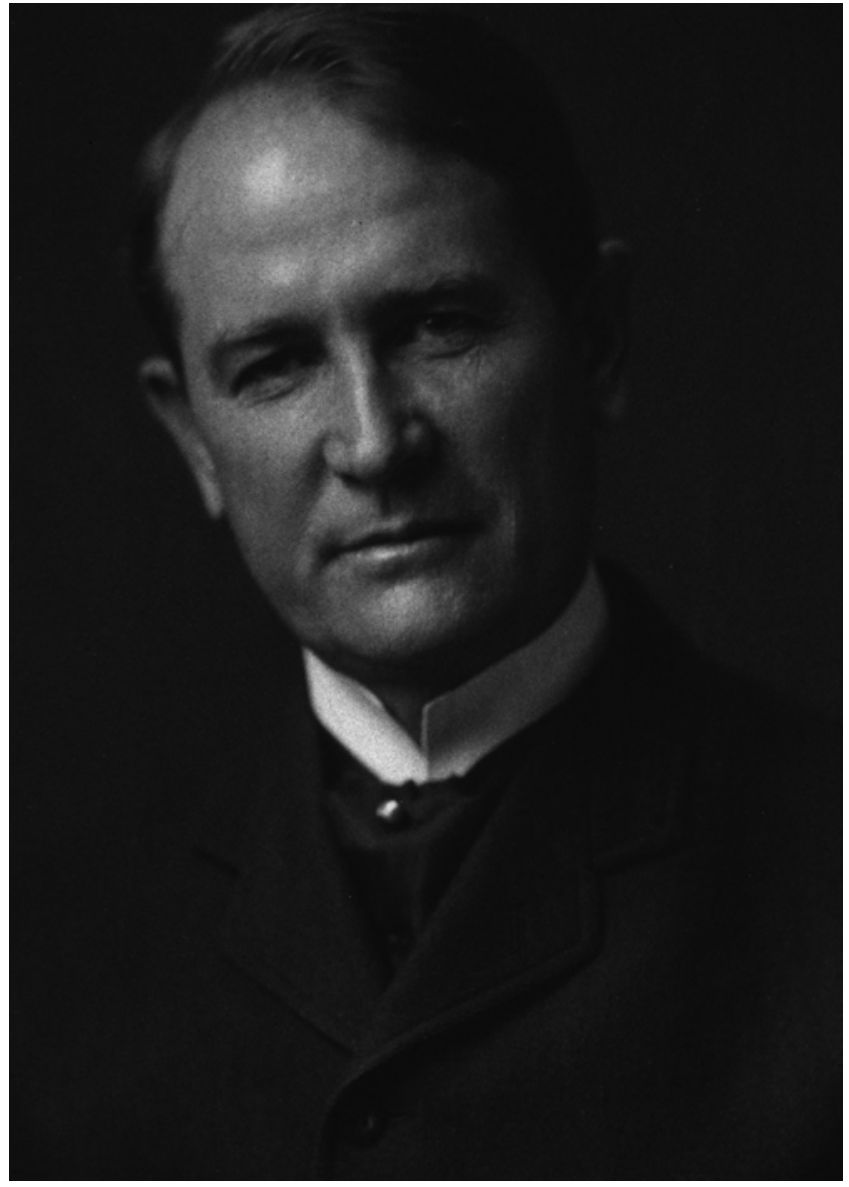

FIG. 1. Sanger Brown. Courtesy of National Library of Medicine. Public domain.

the Royal Society in 1878. In 1887, at the University College of London, he and Sanger presented their observations on neurological dysfunction following temporal lobe removal. Schäfer joined the University of Edinburgh in 1899 as chair of the Physiology Department, founded the British Physiological Society, and was credited with introducing suprarenal extract for clinical use. ${ }^{9}$

Heinrich Klüver (1897-1979) (Fig. 3) was born in Schleswig-Holstein, Germany. He attended the universities of Berlin and Hamburg before going to Stanford University in California and obtaining a $\mathrm{PhD}$ in physiological psychology in 1924. After several years at the University of Minnesota and Columbia University in New York City, Klüver-in 1928, by then an experimental neuropsychologist-moved to Chicago's Institute of Juvenile Research and later to the University of Chicago's Division of Biological Sciences. Particularly interested in primate perception and visual phenomena, in the mid-1930s Klüver began work with neurological surgeon Paul Bucy in producing occipital and later temporal lesions in the monkey. By 1933, Klüver had become an expert on primate behavior and developed sophisticated testing methods on these animals. Together, he and Bucy described the now well-known complex behavioral disorder-Klüver-Bucy syndrome (KBS) - following complete bilateral temporal lobectomy in monkeys. ${ }^{20}$

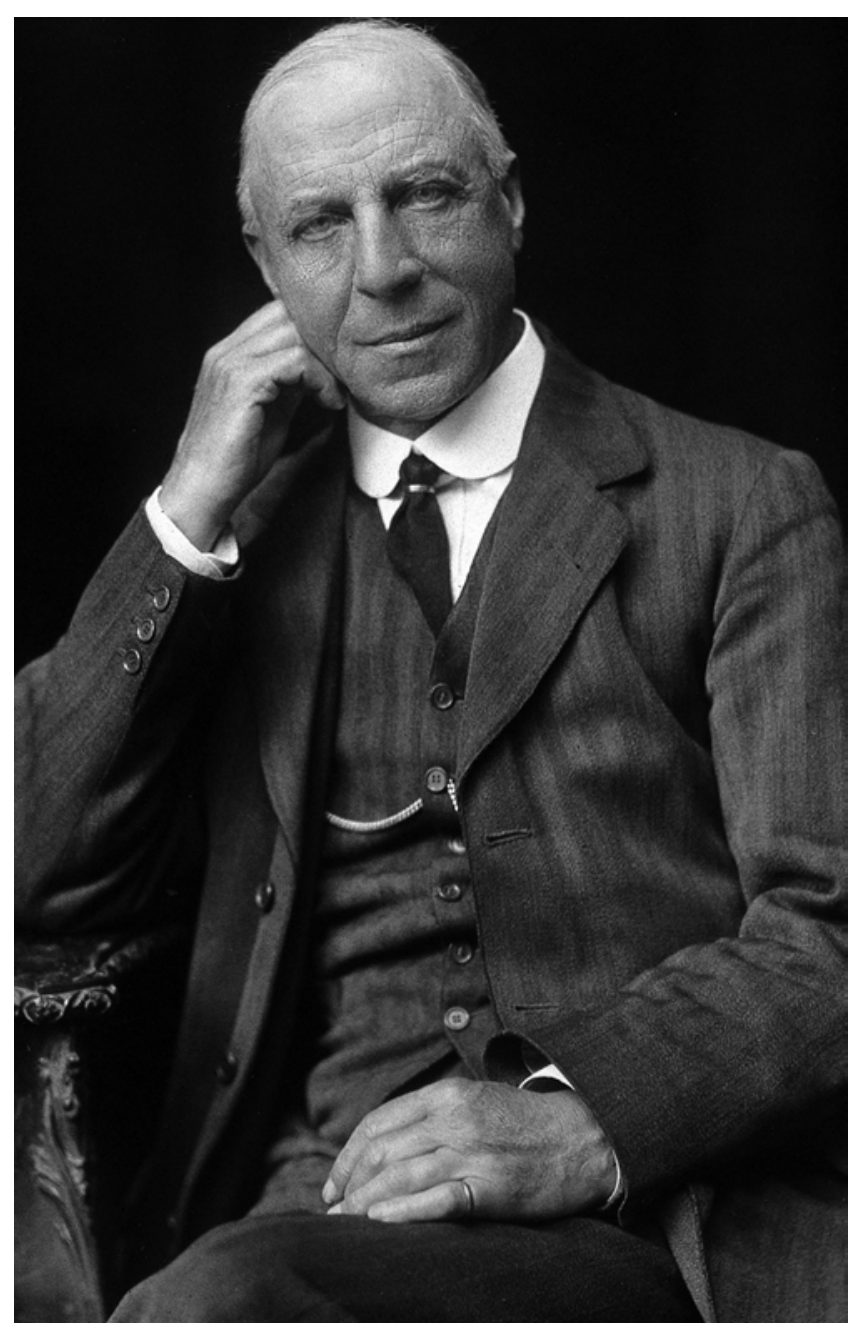

FIG. 2. Edward Albert Sharpey-Schäfer (CC-BY-4.0. (https:// creativecommons.org/licenses/by/4.0/deed.en). Source: Wikipedia.

Paul C. Bucy (1904-1992) was a renowned American neurosurgeon who inspired and trained many neurosurgeons in America and abroad (Fig. 4). After medical school at the University of Iowa, he interned at Henry Ford Hospital in Detroit before beginning neurosurgery training in 1928 at the University of Chicago under Percival Bailey, a noted neuropathologist and surgical trainee of Harvey Cushing. During this period at the University of Chicago, Bucy worked with Klüver to describe KBS in rhesus monkeys. In 1941 he joined Bailey at the University of Illinois at Chicago. Dr. Bucy later moved over to become professor and chair of neurological surgery at Northwestern University in Chicago. ${ }^{5}$

\section{Bilateral Temporal Lobectomy Syndrome of Klüver and Bucy}

The characteristics of this uncommon but interesting syndrome include amnesia, hyperphagia or hyperorality, visual agnosia, and placidity. Memory loss is both anterograde and retrograde, usually profound in nature. There is voracious eating and inappropriate mouthing, with a com- 


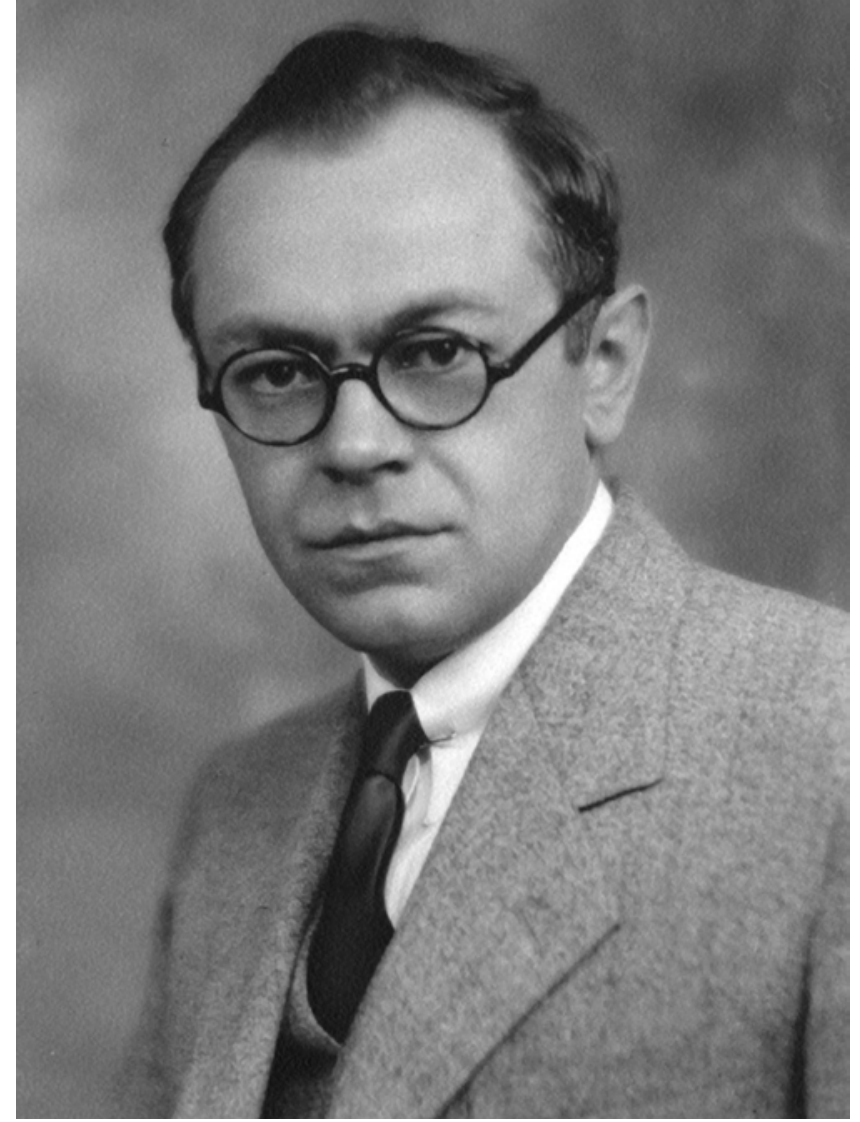

FIG. 3. Heinrich Klüver. With permission from the Special Collections Research Center, University of Chicago Library.

pulsion to devour every object, edible or not. The psychic blindness or visual agnosia is characterized by inability to recognize known objects or people, even with apparently normal vision. The reactions are docile or tame, accompanied by reduced fear and aggression.

Other components include hypermetamorphosis (an irrepressible impulse to notice and respond to every object in the surroundings), emotional flattening or apathy, dampening of emotional expression, memory loss (that would explain the repetitive nature of the actions), altered sexual behavior, and change in dietary habits.

In humans, KBS was first documented in 1955 by Terzian and Ore following temporal lobectomy, ${ }^{23}$ and in 1975 by Marlowe et al. in meningoencephalitis. ${ }^{18}$ Conditions like tumor, trauma, infection, stroke, or bilateral medial temporal lobectomy for refractory seizures can result in temporal lobe dysfunction and KBS. However, seldom is the clinical picture complete in humans. The most common findings are apathy, hyperorality, memory disturbances, and obesity. Agnosia and psychic blindness are observed at times.

\section{The Original Work of Brown and Schäfer}

Brown and Schäfer conducted brain operations in 12 monkeys ( 1 had to be euthanized due to postoperative infection) and presented their observations on December $15,1887 .{ }^{2}$ The work was done predominantly to study the

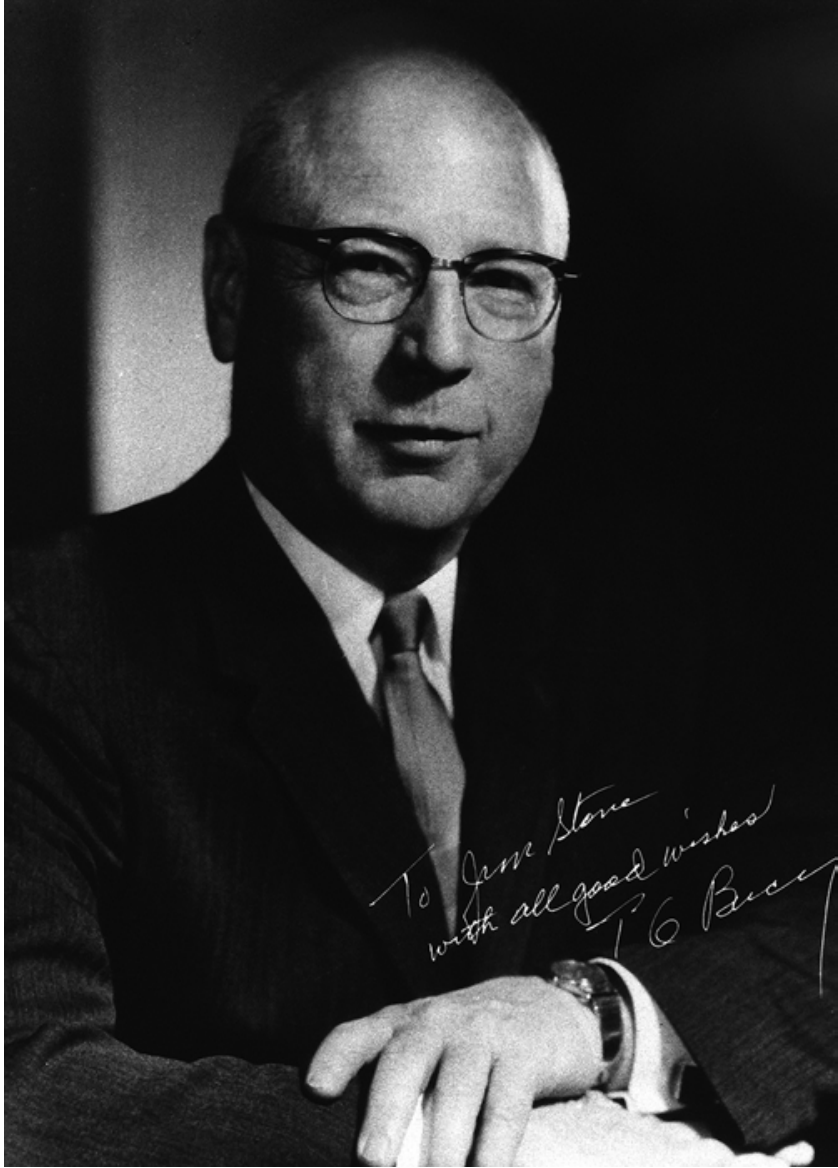

FIG. 4. Paul C. Bucy. Courtesy of Dr. James Stone.

functions of the temporal and occipital lobes and of the angular gyrus.

Among these operations, 2 cases presented interesting observations that in retrospect laid the foundation for the present-day KBS and other functional/behavioral studies..$^{15}$ The following are excerpts from the work of Brown and Schäfer.

Animal 6: This was a Fine, Large, Active Rhesus Monkey

First surgery was complete removal of the right temporal lobe.

Result: Left hemiopia, did not persist for more than a day or two.

Second surgery was performed five days later to remove the left temporal lobe.

Result: complete recovery from the procedure was observed on the day after with a remarkable change in the disposition of the monkey.

Prior to the operations he was very fierce and wild assaulting every person who teased or tried to handle him. Now he voluntarily approaches all persons indifferently, allows himself to be handled, or even to be teased or slapped, without making any attempt at retaliation or endeavouring to escape. His memory and intelligence seem deficient. He gives evidence of hearing, seeing, and of the possession of his senses gener- 
ally, but it is clear that he no longer clearly understands the meaning of the sounds, sights, and other impressions that reach him. Every object with which he comes in contact, even those with which he was previously most familiar, appears strange and is investigated with curiosity. Everything he endeavours to feel, taste, and smell, and to carefully examine from every point of view. This is the case not only with inanimate objects, but also with persons and with his fellow Monkeys. And even after having examined an object in this way with the utmost care and deliberation, he will, on again coming across the same object accidentally even a few minutes afterwards, go through exactly the same process, as if he had entirely forgotten his previous experiments. His food is devoured greedily, the head being dipped into the dish, instead of the food being conveyed to the mouth by the hands in the way usual with Monkeys. He appears no longer to discriminate between the different kinds of food; e.g., he no longer picks out the currants from a dish of food, but devours everything just as it happens to come. He still, however, possesses the sense of taste, for when given a raisin which has been partly filled with quinine he shows evident signs of distaste, and refuses to eat the fruit.

It is also clear that he still both sees and hears. The field of vision appeared at first somewhat limited, and he also seemed to see somewhat indistinctly, making, for example, one or two unsuccessful attempts to pick up a currant from the floor before finally succeeding. This condition, however, soon passed off. He reacts to all kinds of noises, even slight ones, such as the rustling of a piece of paper, but shows no consequent evidence of alarm or agitation, although his attention is evidently attracted by sounds. Thus he was observed to follow with his head the sound of footsteps passing along the corridor just outside his room, directing his attention to them as long as one could oneself distinctly hear them.

This peculiar mental condition was observed for some weeks, becoming gradually less noticeable. A week after the second operation it is noted that he appears brighter in disposition, and is again commencing to display signs of tyrannising proclivities toward his mate, for which he had been remarkable previously. About this time a strange Monkey, wild and savage, was put into the common cage. Our Monkey immediately began to investigate the new comer in the way described, but his attentions were repulsed, and a fight resulted, in which he was being considerably worsted. The animals were, however, separated and tied up away from one another, but our Monkey soon managed to free himself, and at once proceeded, without any signs of fear or suspicion, again to investigate the stranger, having apparently already entirely forgotten the result of his former investigation.

Two weeks after the second operation it is noted that this Monkey continues to 'investigate' objects, but with diminishing frequency and thoroughness. He is either rapidly regaining some of his former experience and memory, or forming altogether new ones. He now takes his food up with his hands, and also pays a more natural attention to his fellows than before. All his senses are acute.

Five weeks after the operation his curiosity has sensibly diminished and he is slowly regaining his former mercurial temperament, continuing, however, tame. This Monkey was kept for nearly eight months after the operation. Long before the expiration of that time he had regained full possession of his mental faculties, and became one of the brightest and most intelligent animals that we had experience of, domineering over all the other Monkeys which were kept in the same cage with him. He was shown to and tested before the Physiologi- cal and Neurological Societies, and was also seen privately by several eminent neurologists. With regard to this Monkey there was no difference of opinion expressed, but it was universally admitted that all his senses, including that of hearing, were perfectly acute. Indeed, it was eventually impossible to detect any abnormality of the cerebral functions.

Autopsy was performed after death following dysentery. In the brain the whole of the temporal lobe is completely removed upon both sides; the lesion extending quite up to the Sylvian fissure on the outer surface, and reaching to the inner edge of the hemisphere on the under surface. On the right side the lesion does not quite reach the parieto-occipital fissure on the external surface, but on the left side the removal extends quite up to this fissure. No trace of the superior temporal gyrus is left on either side, except a part of the grey matter bounding the Sylvian fissure below, and this grey matter is devoid of its corresponding medullary centre. [See Figs. 5-7, which were Fig. 6c, a, and b, respectively, in Brown and Schäfer's paper.]

Brown and Schäfer commented that this was the most extensive bilateral temporal lobectomy they ever performed, remarkable for the immediate loss and ultimate recovery of the intellectual faculties.

\section{Animal 12: A Large, Vigorous Rhesus Monkey}

At the first operation, the left superior temporal convolution was completely removed; this did not produce any appreciable deficit. On the 10th day after this procedure, the right superior temporal gyrus was removed completely

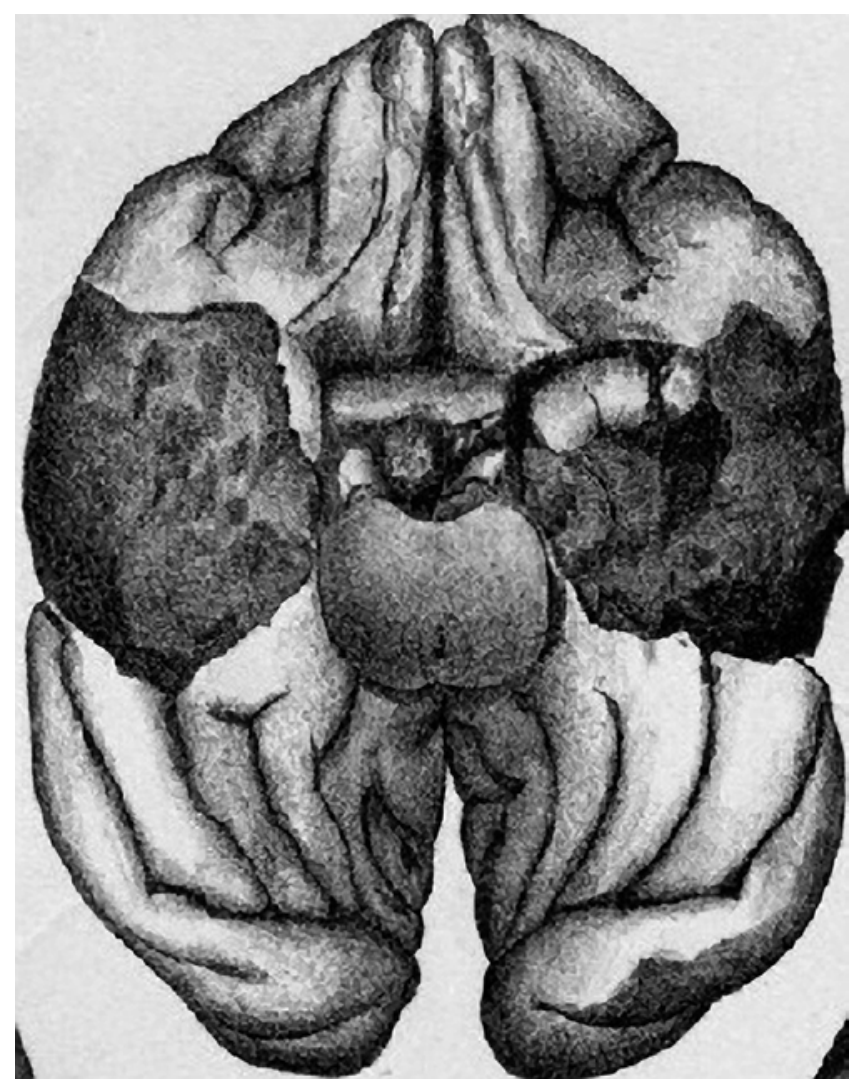

FIG. 5. Drawing of the brain of Brown and Schäfer's Monkey No. 6 , basal view. Permission granted by Royal Society. Orig. fig. 6c. 


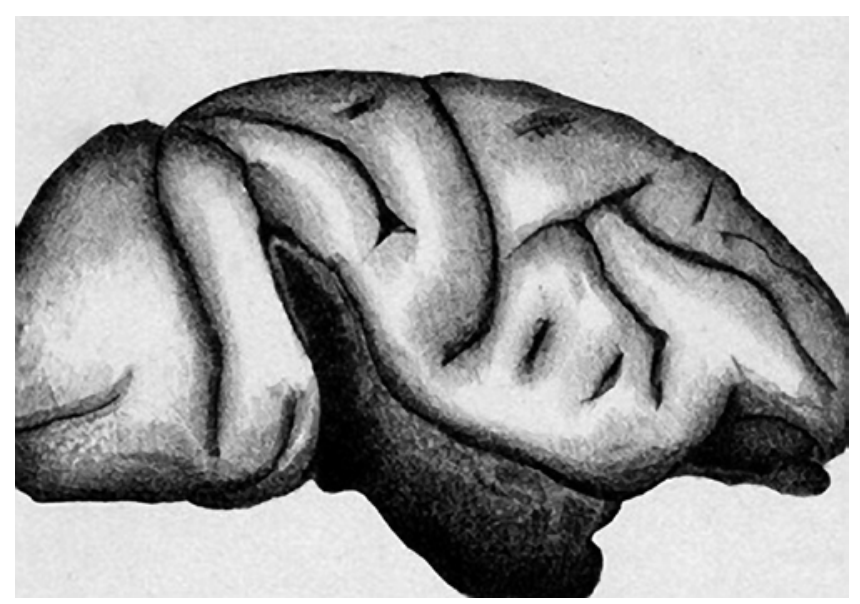

FIG. 6. Drawing of the brain of Brown and Schäfer's Monkey No. 6 (left temporal lobectomy). Permission granted by Royal Society. Orig. fig. 6 a.

(up to the sylvian fissure). Soon after its recovery, the animal was found to give attention to even slight sounds such as kissing or sucking noises made with lips.

But the creature shows the same change of disposition that was manifest in Monkey No. 6. She appears to have lost, in great measure, intelligence and memory. She investigates all objects, even the most familiar, as if they were entirely unknown, tasting, smelling, and feeling all over everything she comes across. She is tame, and exhibits no fear of mankind, but shows uncontrollable passion on the approach of other Monkeys, so that it is now necessary to shut her up in a cage by herself. Like Monkey No. 6, she now invariably devours her food by putting her head down to the platter, instead of employing the hands to convey it to her mouth. Moreover, her appetite is insatiable, and she crams until her cheek-pouches can hold no more. She evidently still sees, hears, tastes, and smells perfectly well, but her understanding of the impressions which she derives from her senses is unquestionably small ... the peculiar idiotic condition into which this Monkey was thrown by the operation was more persistent than in the case of No. 6. Recovery proceeded but gradually; and, although in many points improvement was manifest, there was never, during the whole time that the animal was kept, that complete return of intelligence which was observed in No. 6 (which had, it will be remembered, a much

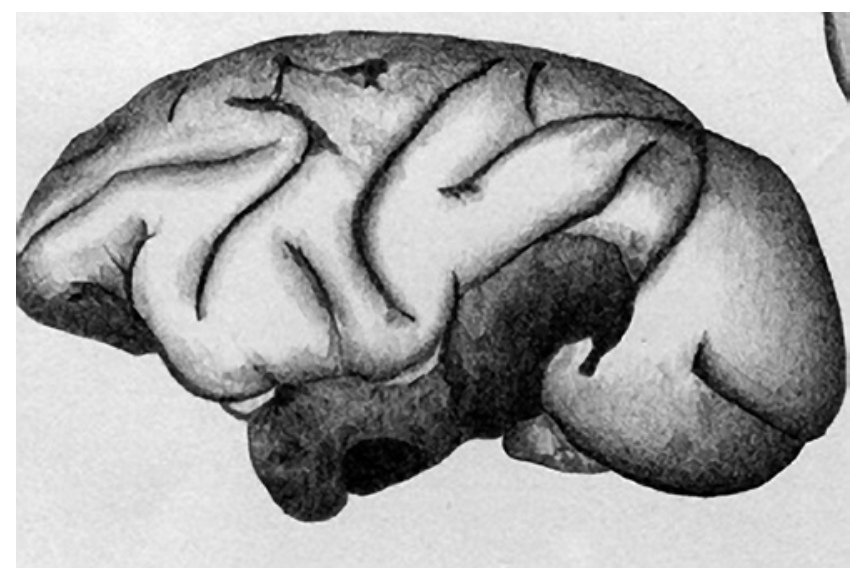

FIG. 7. Drawing of the brain of Brown and Schäfer's Monkey No. 6 (right temporal lobectomy). Permission granted by Royal Society. Orig. fig. 6 b. more extensive bilateral lesion). Her appearance remains stupid, and her movements lethargic; she is still savage towards her fellow Monkeys; her attention is not easily attracted, either by sights or sounds, although an abrupt movement or a sudden and unusual noise will produce signs of perception. She usually takes her food up with her hands, but is still markedly greedy, taking, when she can get it, much more food than a normal Monkey of the same size.

After being kept under observation for more than 8 months, during which she was exhibited to numerous visitors and to the Neurological Society, the animal was killed and its brain examined. At autopsy, bilateral superior temporal gyri were completely removed, and the rest of the brain was normal.

It was noted that in this particular case a comparatively limited bilateral lesion produced a considerable change in the intellectual functions. In Monkey No. 6, the lesion was extensive bilaterally but the loss of intellectual function was far less persistent. Although bilateral superior temporal gyri were removed completely, the animal could hear even the slight sounds; thus findings were conclusive against the localization of auditory function (in the superior temporal gyri).

Brown and Schäfer paid particular attention to these 2 monkeys for the unique deficits displayed following bilateral temporal lobectomy.

Lastly, we would offer a few remarks upon the two remarkable instances in which a bilateral lesion of the temporal lobe has produced a temporary general depression of the intellectual faculties, and has reduced the animals, for a time at least, to a mental condition resembling that of an idiot. In one of the cases (No. 6) this resulted on the complete removal of both lobes, but in the other (No. 12) on the removal of both superior gyri alone. It must, however, be remarked that in the latter instance the operation was conducted in such a manner as to produce a very profound lesion of that part of the hemisphere. The fissures bounding the gyrus (Sylvian and parallel) were drawn open, and the whole of the convolution, in its entire extent and depth, completely shelled out on both sides of the brain. A very great amount of vascular disturbance was thereby necessarily produced, and this must have affected, for a time at least, other portions of the brain.

Probably, therefore, the most reasonable explanation of the general depression of the intellectual faculties which these operations produced is to be found in this vascular disturbance. This, without actually causing the complete paralysis of function of the remainder of the cerebrum, which would have been evidenced by motor paralysis, may yet have sufficed to interfere with the active performance of its functions sufficiently to produce the results described. Thus, in both cases the movements were slow, the senses dulled, the memory very defective, and the disposition changed. It would obviously be unreasonable to assume, certainly in the second case, that these alterations are caused by the local lesion, but it appears to us that they may not unreasonably be explained on the hypothesis we have put forward. The gradual recovery of intelligence in both these animals is extremely interesting, and recalls instances which have been recorded in the human subject in which a gradual recovery has taken place after almost total abolition of the intellectual faculties.

\section{Discussion}

Heinrich Klüver and Paul Bucy in their classic ex- 
perimental work on temporal lobectomy in monkeys observed similar behavioral findings beginning with their first animal. They reproduced the work of Brown and Schäfer, but very likely with more meticulous neurosurgical and behavioral observational techniques. Several years after these first bilateral temporal lobectomies, ${ }^{12,14,16}$ Klüver came across Brown and Schäfer's 1888 reference after a search of the world literature, and the "two monkeys exhibiting essentially the same symptoms I have described."13 In 1951, Klüver remarked, "It is evident that the observation of Brown and Schäfer agree fully with ours, particularly with reference to the picture of psychic blindness, the oral tendencies, the 'hypermetaphosis,' and the striking changes in emotional behavior. Although there is a striking agreement as regards the description of the symptoms, I cannot agree with the interpretation of the authors that these symptoms are indicative of a condition resembling 'general idiocy." However, anyone who has ever seen the truly remarkable behavior changes following bilateral temporal lobectomy will not be surprised to learn that Brown and Schäfer felt called upon to demonstrate their 2 monkeys before various scientific societies. ${ }^{2,21}$ In fact, these 2 animals were exhibited to London's Neurological Society, where a committee was appointed to examine them. ${ }^{21}$

\section{The Schäfer-Ferrier Feud}

As regards the lesions that produced these changes in behavior, David Ferrier expressed the opinion that Schäfer's published diagrams of the brains of these monkeys "must be regarded more as a sort of pictorial representation of his own idea, or wish, as to the extent of the lesions, rather than of the reality."7 Schäfer, who had claimed, for instance, he removed "the whole of the temporosphenoidal lobe, including the hippocampus," on both sides, was fortunately able to publish photographs of these brains. It is evident from these photographs that the bilateral lesions, for example, in Monkey 6 were comparable in extent to the lesions produced in KBS experiments. ${ }^{13,21,22}$

At this time Ferrier believed that the parietal lobe, notably the angular gyrus, in primates was the site for primary visual reception, and Schäfer believed that the occipital lobe performed this function. Schäfer also presented his observations that after temporal lobectomy, hearing was intact in these monkeys. Possibly this happened, because the inferior colliculus, medial geniculate body, and the auditory apparatus were still intact! Ferrier, however, did not believe this.

Ferrier strongly wrote, "The opponents of cerebral localization-a race well-nigh extinct-make capital out of the fact, that the advocates of this doctrine are not agreed among themselves as to the exact extent of the areas or regions supposed to be endowed with specific functions. They will therefore welcome with satisfaction the contribution to the physiology of the cerebral hemispheres, by Professor Schafer."7

One may be reminded here about Schäfer's important and well-respected work with his student Victor Horsley ("A record of experiments upon the functions of the cerebral cortex"), where they used electrical excitation and ab- lation in several monkeys; ${ }^{11}$ much of this work was verified in future studies performed by other investigators.

Schäfer replied: "I should have been content to pass Dr. Ferrier's polemical article ... in silence, were it not that the author directly contravenes the accuracy of the descriptions which I have given of the post-mortem condition of certain of the brains which had been operated on by Dr. Sanger Brown and myself, and indirectly accuses me of falsifying the representations which I have given in my paper." ${ }^{22}$ He continued: “... whatever may have been the case in Dr. Ferrier's own investigations, this has certainly not happened in the experiments in which I have been engaged in conjunctions with Mr. Horsley or with Dr. Brown, as longitudinal sections through the hemispheres have abundantly shown.",2,11

Schäfer was very respectful in his response to Ferrier: "I share to the full the regret which Dr. Ferrier feels for the attitude I have taken up on this question, but not for my own sake nor for that of the truth. Few men have done so much toward the elucidation of the cerebral functions as my present opponent." 22 In 1878, Hughlings Jackson joined David Ferrier as founding editor of the journal Brain, but did not interact on the topic.

Ferrier also refuted the experimental observations of Hermann Munk (1839-1912) from Berlin on visual localization, although he had to retreat from his own observations, as "this being a partial truth is an error."' Munk coined the term "psychic blindness," which remained in use ${ }^{13}$ although it was more appropriately named "agnosia" by Sigmund Freud in $1891 .{ }^{8}$

After returning from London, Brown continued his visual work in dogs, cats, and several monkeys in New York City at the Loomis Research Laboratory. This work further established the occipital lobe as the visual center. ${ }^{24}$

Nearly 50 years later, Bucy and Klüver described the psychological abnormalities with a greater detail and meticulous evaluations. $3,13,15,19$

The behavioral effects of the removal of both temporal lobes, including the uncus and the greater part of the hippocampus, were studied in macaques. The monkeys exhibited the following symptoms: 1) forms of behavior which seem to be indicative of "psychic blindness;" 2) strong oral tendencies in examining available objects (licking, biting gently, chewing, touching with the lips, "smelling"); 3) a strong tendency to attend and react to every visual stimulus ("hypermetamorphosis"); 4) marked changes in emotional behavior or absence of emotional reactions in the sense that the motor and vocal reactions generally associated with anger and fear are not exhibited; and 5) an increase in sexual activity.

The symptoms typical of monkeys with both temporal lobes removed did not appear after partial temporal lobe removals or disconnection with occipital lobe. The symptoms also did not appear after unilateral temporal lobectomy, except that there was in some cases a change in the direction of greater "tameness." This "tameness" was also observed when after previous extirpation of both prefrontal areas one temporal lobe was removed. Differential reactions to visual stimuli established preoperatively were seriously disturbed after bilateral temporal lobectomy, but it was possible to reestablish the response through training.

Addressing the Chicago Neurological Society in 1940, Bucy mentioned Brown as one of the founders and the first 
president of that society. Also, he gave credit to Brown's work with Schäfer at the University College, London, stating, "... it is extraordinarily appropriate that this subject should be presented to the Chicago Neurological Society." ${ }^{4,17}$

Klüver came to Chicago and started working with Bucy in the early 1930s. By that time Brown had died. There is no record of any meeting between Brown and Bucy or Klüver.

\section{Further Work by Other Investigators of KBS}

Beginning in the 1950s, other neuroscientists, most notably Karl Pribram, a board-certified neurosurgeon trained by Bucy who later became a highly productive experimental neuropsychologist and neurophysiologist, along with his graduate students and coworkers, would determineby neurosurgical ablation followed by careful behavioral techniques-the specific areas of the temporal lobe responsible for the various aspects of KBS. These included the posterior temporal cortical visual associative regions; limbic system structures such as the amygdala, hippocampus, and associated areas; and fiber tracts. ${ }^{8,24}$ Subsequently, work in monkeys has demonstrated that KBS is largely the result of bilateral amygdala lesions. ${ }^{1}$

\section{Conclusions}

In the late 1880s, Sanger Brown and Edward Schäfer performed a systematic study of occipital and temporal cerebral cortical excisions in 12 monkeys to establish the functions of these regions. Ferrier, who believed that the parietal angular gyrus was the center of vision and the superior temporal gyrus was the center of hearing, refused to accept their observations, despite the fact that these monkeys were being displayed at the London meetings of the neurological and physiological societies.

The work of Klüver and Bucy verified the findings of Brown and Schäfer and greatly expanded on these findings and the unusual behavioral constellation. It was accepted as remarkable that bitemporal destruction can result in consistently reproducible emotional disorder and complex visual behavior. Even though KBS came at a time when Freudian psychotherapy was popular, it indirectly led to a new spectrum of neuroscientific and psychological thought; that destructive lesions within the limbic system could be helpful in treating certain psychological conditions.

\section{References}

1. Aggleton JP, Passingham RE: Syndrome produced by lesions of the amygdala in monkeys (Macaca mulatta). J Comp Physiol Psychol 95:961-977, 1981

2. Brown S, Schäfer EA: An investigation into the functions of the occipital and temporal lobes of the monkey's brain. Philos Trans R Soc Lond 179B:303-327, 1888

3. Bucy PC, Klüver H: An anatomical investigation of the temporal lobe in the monkey (Macaca mulatta). J Comp Neurol 103:151-251, 1955

4. Bucy PC, Klüver H: Anatomic changes secondary to temporal lobectomy. Arch Neurol Psychiatry 44:1142-1146, 1940

5. Dohrmann GJ: Dr. Paul Bucy and the M.D./Ph.D. program. Surg Neurol 59:232-233, 2003
6. Ferrier D: The Functions of the Brain. London: Smith, Elder, 1886

7. Ferrier D: Schäfer on the temporal and occipital lobes. Brain 11:7-30, 1888

8. Gross CG: From Imhotop to Hubel and Wiesel. The story of the visual cortex, in Rockland KS, Kaas JH, Peters A (eds): Cerebral Cortex. Vol 12. Extrastriate Cortex in Primates. New York: Springer, 1997, pp 1-58

9. Hill L: Obituary. Sir Edward Sharpey-Schafer, F.R.S. BMJ 1:741-742, 1935

10. Hinsdale G: Memorial. Sanger Brown, M.D. Trans Am Climatol Clin Assoc 44:xxvi-xxvii, 1928

11. Horsley V, Schäfer EA: A record of experiments upon the functions of the cerebral cortex. Philos Trans R Soc Lond B Biol Sci 179:1-45, 1888

12. Klüver H: Certain effects of lesions of the occipital lobes in monkeys. J Psychol 4:383-401, 1937

13. Klüver H: Functional differences between the occipital and temporal lobes - with special reference to the interrelations of behavior and extracerebral mechanisms, in Jeffress LA (ed): Cerebral Mechanisms in Behavior. New York: Wiley, 1951

14. Klüver H, Bucy PC: An analysis of certain effects of bilateral temporal lobectomy in the rhesus monkey, with special reference to "psychic blindness." J Psychol 5:33-54, 1938

15. Klüver H, Bucy PC: Preliminary analysis of functions of the temporal lobes in monkeys. Arch Neurol Psychiatry 42:979-1000, 1939

16. Klüver H, Bucy PC: "Psychic blindness" and other symptoms following bilateral temporal lobectomy in Rhesus monkeys. Am J Physiol 119:352-353, 1937

17. Magoun HW, Marshall LH: American Neuroscience in Twentieth Century. Confluence of the Neural, Behavioral and Communicative Streams. London: Taylor \& Francis, 2003, p 300

18. Marlowe WB, Mancall EL, Thomas JJ: Complete KlüverBucy syndrome in man. Cortex 11:53-59, 1975

19. Nahm FKD: Heinrich Klüver and the temporal lobe syndrome. J Hist Neurosci 6:193-208, 1997

20. Nahm FKD, Pribram KH: Heinrich Klüver: Biographical Memoir. Washington, DC: National Academies Press, 1998

21. Schäfer EA: Experiments on special sense localisations in the cortex cerebri of the monkey. Brain 11:362-380, 1888

22. Schäfer EA: On the functions of the temporal and occipital lobes: a reply to Dr. Ferrier. Brain 11:145-165, 1888

23. Terzian H, Ore GD: Syndrome of Klüver and Bucy; reproduced in man by bilateral removal of the temporal lobes. Neurology 5:373-380, 1955

24. Thompson WG, Brown S: Center for vision. Res Loomis Laboratory 1:13-37, 1890

\section{Disclosures}

The authors report no conflict of interest concerning the materials or methods used in this study or the findings specified in this paper.

\section{Author Contributions}

Conception and design: both authors. Acquisition of data: both authors. Drafting the article: both authors. Critically revising the article: both authors. Reviewed submitted version of manuscript: both authors. Approved the final version of the manuscript on behalf of both authors: Vannemreddy.

\section{Correspondence}

Prasad Vannemreddy, Department of Neurosurgery, University of Illinois at Chicago, 912 S Wood St., Chicago, IL 60612. email: prasad4458@hotmail.com. 